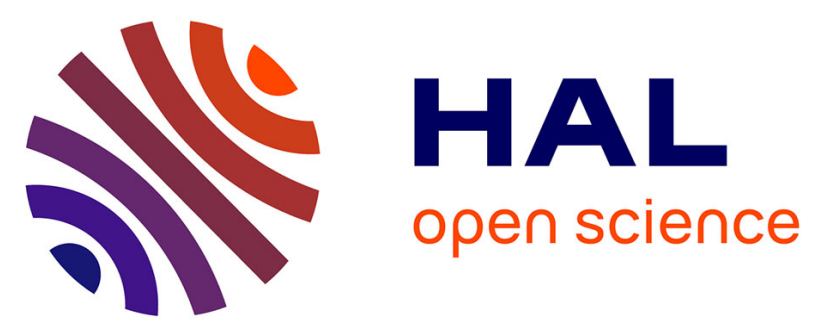

\title{
Structural Dynamics upon Photoexcitation in a Spin Crossover Crystal Probed with Femtosecond Electron Diffraction
}

Yifeng Jiang, Lai Chung Liu, Henrike M. Müller-Werkmeister, Cheng Lu, Dongfang Zhang, Ryan L. Field, Antoine Sarracini, Gustavo Moriena, Eric Collet, R.J. Dwayne Miller

\section{To cite this version:}

Yifeng Jiang, Lai Chung Liu, Henrike M. Müller-Werkmeister, Cheng Lu, Dongfang Zhang, et al.. Structural Dynamics upon Photoexcitation in a Spin Crossover Crystal Probed with Femtosecond Electron Diffraction. Angewandte Chemie International Edition, 2017, 56 (25), pp.7130-7134. 10.1002/anie.201702497 . hal-01523791

\section{HAL Id: hal-01523791 \\ https://hal.science/hal-01523791}

Submitted on 9 Oct 2017

HAL is a multi-disciplinary open access archive for the deposit and dissemination of scientific research documents, whether they are published or not. The documents may come from teaching and research institutions in France or abroad, or from public or private research centers.
L'archive ouverte pluridisciplinaire HAL, est destinée au dépôt et à la diffusion de documents scientifiques de niveau recherche, publiés ou non, émanant des établissements d'enseignement et de recherche français ou étrangers, des laboratoires publics ou privés. 


\title{
Structural Dynamics upon Photoexcitation in a Spin Crossover Crystal probed with Femtosecond Electron Diffraction
}

\author{
Yifeng Jiang ${ }^{1}$, Lai Chung Liư², Henrike M. Müller- Werkmeister ${ }^{1}$, Cheng Lu², Dongfang Zhang ${ }^{1}$, Ryan L. \\ Field $^{2}$, Antoine Sarracini ${ }^{2}$, Gustavo Moriena ${ }^{2}$, Eric Collet $^{3}$, R. J. Dwayne Miller ${ }^{1,2 *}$ \\ ${ }^{1}$ Max Planck Institute for the Structure and Dynamics of Matter Luruper Chaussee 149, 22607, Hamburg, Germany \\ 2 Departments of Chemistry and Physics, University of Toronto, 80 St. George Street, Toronto, Ontario, M5S 3H6, Canada \\ ${ }^{3}$ Université Rennes 1, CNRS, Institut de Physique de Rennes, UMR 6251, UBL, F-35042 Rennes, France
}

\begin{abstract}
Photoexcitation of spin crossover (SCO) complexes can trigger extensive electronic spin transitions and transformation of molecular structure. However, the precise nature of the associated ultrafast structural dynamics remains elusive, especially in the solid state. Here, we studied a single crystal SCO material with femtosecond electron diffraction (FED). The unique capability of FED allows us to directly probe atomic motions and to track ultrafast structural changes within a crystal lattice. By monitoring the time-dependent changes of the Bragg reflections, we observed the formation of a photoinduced structure similar to the thermally induced high-spin state. The data and refinement calculations indicate the global structural reorganization within $2.3 \mathrm{ps}$, as the metal-ligand bond distribution narrows during intramolecular vibrational energy redistribution (IVR) driving the intermolecular rearrangement. Three modes are identified to model the structural dynamics upon photoinduced SCO.
\end{abstract}

The current industrial drive towards device miniaturization has created considerable interest in switchable molecular systems. Among these are transition metal complexes, which show great promise in various domains, such as molecular electronics, highdensity magnetic data storage, data displays, and dye-sensitized solar cells. ${ }^{[1]}$ They exhibit a reversible phase transition, known as SCO, between a low-spin (LS) and a high-spin (HS) state that can be triggered externally through pressure, temperature, magnetic fields, or light. ${ }^{[2,3]}$ In particular, the photoinduced case has been intensely studied in iron(II)- complexes and it has been found to occur in solution ${ }^{[4]}$ and in the solid state (doped lattices, nanocrystals, and bulk crystal). ${ }^{[5-7]}$

The ultrafast photoinduced dynamics of solvated SCO complexes have been studied using X-ray spectroscopies ${ }^{[8-11]} \mathrm{X}$-ray scattering, ${ }^{[12]}$ Raman spectroscopy ${ }^{[13]}$ and transient absorption spectroscopies. ${ }^{[14,15]}$ The relaxation process leading to SCO in these compounds proceeds from an initial excitation from the ${ }^{1} A_{1}$ LS state into the metal-to-ligand charge-transfer (MLCT) manifold, from which the system relaxes to the ${ }^{5} \mathrm{~T}_{2}$ HS state within $<200$ fs via multiple intersystem crossings. ${ }^{[15-17]}$ From the HS state, the vibrationally hot molecule is believed to relax through IVR within $\sim 1-2$ ps. $^{[15,16]}$ In solids, ultrafast photoinduced SCO has been investigated using ultrafast time-resolved XANES ${ }^{[17,18]}$, transient reflectivity, transient absorption and femtosecond magneto-optical Faraday spectroscopy. ${ }^{[16-20]}$ Picosecond X-ray diffraction ${ }^{[21]}$ and time-resolved optical spectroscopy ${ }^{[22]}$ have been applied to track further processes much later after photoexcitation. These studies suggest that, for SCO compounds with both thermal and photoinduced SCO, the early $<10$ ps ultrafast dynamics in crystals are due to photoinduced dynamics in a manner comparable to those observed in solution, while the late-time, $>0.1 \mathrm{~ns}$ changes in HS fraction are driven by cooperative elastic and thermal processes. ${ }^{[21,22]}$

The structure of a Fe(II) metal compound ([Fe(PM-AzA $\left.)_{2}\right](\mathrm{NCS})_{2}$ cis-bis(thiocyanato)-bis(N-2'-pyridyl-methylene)-4-phenyl-azo) aniline iron(II)) is shown in Figure 1a. It undergoes thermally induced SCO at $\mathrm{T}_{1 / 2}=184 \mathrm{~K},{ }^{[18,19]}$ as shown in Figure $\mathrm{S} 1$ in Supplementary Information (SI). The photoinduced SCO in single crystalline [Fe(PM-AzA $\left.)_{2}\right](\mathrm{NCS})_{2}$ has previously been identified as a two-step ISC process with a fast (<200 fs) relaxation process through short-lived intermediate states (INT) followed by IVR within the photoinduced HS state on a timescale of $\sim 2$ ps $^{[18,19]}$ Recent ultrafast dynamics studies ${ }^{[9,12,17-19]}$ have concluded that the Fe-N bond elongation is directly correlated in time (200 fs) to the electronic state dynamics observed by changes in the spectral features of the complex, followed by IVR. However, previous picosecond X-ray diffraction studies ${ }^{[21]}$ underlined that the structural rearrangement inside the unit cell, through inter-molecular contact, is a much more complex process and direct femtosecond structural studies on the overall photoinduced SCO are lacking, despite indirect information gained from different experiments ${ }^{[21]}$.

Femtosecond electron diffraction (FED) directly probes atomic positions by scattering off the Coulomb potential of the nuclei, ${ }^{203-}$ ${ }^{27]}$ capable of resolving the above issues related to the structural relaxation associated with spin transitions. FED is employed in a pump-probe protocol, using femtosecond laser pulses to trigger the ultrafast dynamics and femtosecond electron pulses to probe the resulting nuclear motions (Figure 1b). Here, we reveal the structural dynamics upon photoexcitation during the IVR that accompanies the spin-state switching with high spatial precision, which is specific to FED and in contrast to X-ray diffraction due to its shorter carrier wavelength for probing atomic motions.

FED experiments were performed with excitation conditions similar to the previously reported optical pump-probe reflectivity studies. ${ }^{[18,19]}$ Samples were kept at $170 \mathrm{~K}$, pumped at $800 \mathrm{~nm}$ (pulse duration $=60 \mathrm{fs}$, fluence $=1.28 \mathrm{~mJ} \mathrm{~cm}^{-2}$ ), and probed by $267 \mathrm{fs}$ electron pulses. To allow full recovery of the sample from HS to LS $(<1 \mathrm{~ms}),{ }^{[19]}$ the repetition rate was set to $100 \mathrm{~Hz}$. At the fluence used, no damage over the duration of the experiment was observed, see SI for additional information and results from control experiments.

Figure $2 \mathrm{a}$ shows a static diffraction pattern of $\left(\left[\mathrm{Fe}(\mathrm{PM}-\mathrm{AzA})_{2}\right](\mathrm{NCS})_{2}\right.$ at $170 \mathrm{~K}$. Figure $2 \mathrm{~b}$ depicts the change of the static electron diffraction patterns corresponding to the structural changes associated with the thermal phase transition, from below $\mathrm{T}_{1 / 2}$ or 'low-temperature' ( $\mathrm{LT}, \mathrm{T}=170 \mathrm{~K}$ ) to above $\mathrm{T}_{1 / 2}$ or 'high-temperature' ( $\mathrm{HT}, \mathrm{T}=300 \mathrm{~K}$ ). The observed change in the Bragg peak 
intensities and positions are closely related to those resulting from the photoinduced transition. The difference patterns resulting from photoinduced SCO (measured at $170 \mathrm{~K}$ and time delay $\mathrm{t}=+10 \mathrm{ps}$ ) are shown in Figure 2c. They match the expected Bragg peak intensity changes simulated using the LS and HS X-ray structures in Figure 2d. Figure 3a gives the transient behavior of some selected Bragg spots for the short timescale (-5-22 ps) and Figure 3b for the longer timescale (-50-1000 ps).

The most noteworthy feature in Figure $3 a$ is that the intensity of all observed Bragg peaks change exponentially, decaying or rising with almost the same time constant of $2.3 \mathrm{ps}$. In SI Section 6, further discussion and analysis is presented to support this observation. We also note that, for Bragg peaks $(h=k=0, I \neq 0)$ such as $(002),(004)$, and $(006)$, the shifts in peak positions have the same time constant as the changes in the peak intensity. These displacements are consistent with a local expansion of the unit cell that takes places concurrently with the ultrafast nuclear motions.

Previous literature ${ }^{[17-19]}$ suggests an ultrafast Fe-N bond elongation after photoexcitation, but only slow Fe-N bond elongation is observed in our measurement. To unravel the underlying structural changes responsible for this transient behavior, we calculated the structure factor changes for a selection of the Bragg peaks. Two possible pathways for atomic motions were considered. The first model (Figure 4a) involves only the $<200$ fs ultrafast Fe-N bond elongation. Figure $4 b$ shows the corresponding simulated diffraction intensities. Alternatively, we considered a second model where the Fe-N bond elongation is coupled to ligand motion, and local unit cell expansion (Figure 4c) upon IVR of the hot excited HS state; the calculated intensities for this scenario are shown in Figure 4d. Clearly, the structure values of the former case do not match the experimentally observed difference pattern (shown in Figure 4e) while those of the latter do match relatively well.

We calculated the contributions of different molecular motions to the observed Bragg peak intensities. For select peaks, these values are shown in Figure 5. The ligand motion is the major contributor to the change in intensity: (111) is purely based on ligand motion while all other peaks, most dominantly $(\mathbf{1 1 0}),(\mathbf{0 0 2})$, and $(330)$ have weighted contributions of Fe-N bond elongation and ligand motion. The intensities of these Bragg peaks should exhibit bi-exponential behavior due to a fast Fe- $\mathrm{N}$ bond elongation, driving intensity change within the $\sim 300$ fs time resolution, and the ligand motion occurring in the following 2 ps, an effect which we did not observe experimentally (Figure 3a).

The time constant of our observations matches the timescale of IVR. ${ }^{[2]}$ Previous work using transient UV-VIS spectroscopy observed the narrowing of the excited state absorption feature with a 2 ps time constant, ${ }^{[14,20]}$ while recent XANES work ${ }^{[29]}$ suggests that $\mathrm{Fe}-\mathrm{N}$ bond distribution after photoexcitation narrows on the same timescale as spectral features associated with IVR. Our results are therefore consistent with previous findings and can be explained by IVR of hot excited HS molecules and energy transfer from $\mathrm{Fe}-\mathrm{N}$ stretching motions to the rearrangements of the ligands and the unit cell. Indeed, after photoexcitation, the LS molecule converts into the HS state in 200 fs timescale with a great deal of excess energy, activating coherent and incoherent molecular vibrations, as observed by a related XANES study by Lemke et al. ${ }^{[29]}$ Therefore, the energy dissipation through ligand rearrangement associated with this process would occur on the timescale of IVR. Similarly, the motion of the ligands causes extension of the molecule in the unit cell, driving local unit cell expansion through intermolecular contracts. The resulting elastic stress field acts as a chemical pressure to the whole crystal. $^{[30]}$ Thus, the apparent slow Fe-N bond elongation can be explained by the 2 ps bond distribution narrowing during IVR, which modifies the relative weight of Fe- $\mathrm{N}$ and ligand rearrangements in diffracted intensity, since the electron diffraction probes the ensemble average of the $\mathrm{Fe}-\mathrm{N}$ bond lengths.

We should underline that the ultrafast structural transition studied here is a purely light-induced SCO process. Although deposited laser energy in the crystal lattice can also result in thermal SCO and lattice expansion, this only happens with inhomogeneous lattice expansion between $10 \mathrm{~ns}$ and $10 \mu \mathrm{s}$, followed by homogenized crystal expansion and heat-induced SCO at $50 \mu$ s. $^{[21,22]}$

Another noteworthy feature in Figure $3 a$ is the plateau behavior observed for time delay from 5 ps to 24 ps. This is indicative of the formation of the excited HS structure further supporting our model (as illustrated in Figure 4c). To obtain a time-dependent map of the molecular motions during SCO, we applied a structural refinement algorithm based on a parameterized molecular model. ${ }^{[23]}$ The structural transformation from the LS to HS states can be decomposed into three independent dynamical groups: Fe-N bond elongation $(\mathrm{N})$; ligand motion to HS structure $(\mathrm{L})$; unit cell expansion $(\mathrm{U})$. The term $\xi$ is an atomic structural parameter composed of the three time-dependent generalized reaction coordinates $\left(\xi_{N} \xi_{L} \xi_{U}\right)$ assigned to the motion of these groups.

Figures $6 a-c$ depict the three key dynamical groups as a function of time, representing the ultrafast structural dynamics. The time constant of these key modes is $2.3 \mathrm{ps}$. The time-dependent changes of $\xi$ are summarized in Figure $6 \mathrm{~d}$. The reaction coordinates of three motions represent relative atomic motions from the initial LS state at $\xi=(0,0,0)$ to towards the final HS state at $\xi=(1,1,1)$. Previous picosecond X-ray diffraction studies on later processes associated with SCO indicate a local excited HS molecule within a LT unit cell, which subsequently changes to a HT unit cell through molecular rearrangement. ${ }^{[21,22]}$ Here, we find that the photoexcited HS structure, with $\xi=(0.9,0.8,0.75)$, is similar but distinct from the thermal HS structure since the photoexcited HS molecule is constrained inside the smaller LT unit cell. We experimentally detect a local unit cell expansion on the ultrafast timescale, which is induced by the $\mathrm{Fe}-\mathrm{N}$ bond elongation and ligand motion through intermolecular elastic interaction, which was not observed in previous studies. This is of key interest to understand how IVR and light-induced intermolecular forces within the unit cell drive lattice expansion that is subsequently responsible for cooperative elastic spin-state switching. ${ }^{[1]}$

The full relaxation pathway and physical picture based on this atomically resolved structural transition is shown in Figure 7 . The initial intersystem crossing occurs through Franck Condon factors, weighted by the overlap in the MLCT manifold, that creates a highly excited vibrational superposition state that then undergoes IVR and narrowing of the Fe-N bond distribution to the fully relaxed configuration on the timescale of IVR. ${ }^{[16,28]}$

In this study, the ultrafast structural changes associated with photoinduced SCO in $\left[\mathrm{Fe}(\mathrm{PM}-\mathrm{AzA})_{2}\right](\mathrm{NCS})_{2}$ have been directly characterized for the first time using FED with near-uniform sample excitation. The electron probe used is uniquely sensitive to changes in the crystal structure of the sample following photoexcitation. The photoinduced structural changes between LS and HS states are very similar to the ones observed at thermal equilibrium, which is not always the case as symmetry breaking was reported in some photoinduced states. ${ }^{[31-34]}$ These global changes (Fe-N bond elongation, ligand motions, and local unit cell expansion) were 
all found to share the same time constant $(2.3 \mathrm{ps})$. The structural dynamics can be fully modelled by three key modes, such that the atomic motions induced by IVR after SCO are monitored with ultrafast temporal resolution and atomic spatial resolution. The picture that emerges is consistent with previous studies while fully depicting the relaxation processes to the HS state.

Acknowledgements: The authors thank G. Sciaini and H. D. Pinto for helpful discussions. This research was supported by the Natural Sciences and Engineering Research Council of Canada (NSERC, L. L., R. J. D. M.), the Max Planck Society and the excellence cluster "The Hamburg Centre for Ultrafast Imaging - Structure, Dynamics and Control of Matter at the Atomic Scale" of the Deutsche Forschungsgemeinschaft (R. J. D. M.), by the ANR (ANR-13-BS04-0002, E.C) and the People Programme (Marie Curie Actions) of the European Union's Seventh Framework Programme (FP7/2007-2013) under REA grant agreement no. 623994 (H. M.-W.). We declare no conflict of interest.

Keywords: spin crossover $•$ photochemistry $\cdot \mathrm{N}$ ligands $\cdot$ electron diffraction $\bullet$ structure elucidation

[1] C. Brady, J. J. McGarvey, J. K. McCusker, H. Toftlund, D. N. Hendrickson, Spin Crossover in Transmission Metal Compounds III (Eds.: P. Gütlich, H. A. Goodwin), 2004, Springer-Verlag, Berlin, pp. 1-22.

[2] A. Bousseksou, G. Molnar, L. Salmon, W. Nicolazzi, Chem. Soc. Rev. 2011, 40, 3313.

[3] J. A. Real, A. B. Gaspar, M. C. Muñoz, Dalton Trans. 2005, 12, 2062.

[4] R. Bertoni, M. Lorenc, A. Tissot, M. Servol, M.-L. Boillot, E. Collet, Angew. Chem. Int. Ed. 2012, 51, 7485; Angew. Chem. 2012, 124, 7603.

[5] M. A. Halcrow, Polyhedron 2007, 26, 3523

[6] J. Tribollet, G. Galle, G. Jonusauskas, D. Deldicque, M. Tondusson, J.-F. Létard, E. Freysz, Chem. Phys. Lett. 2011, $513,42$.

[7] R. M. van der Veen, O.-H. Kwon, A. Tissot, A. Hauser, A. H. Zewail, Nat. Chem. 2013, 5, 395.

[8] Ch. Bressler et al,Science 2009, 323, 489.

[9] W. Zhang et al, Nature 2014, 509, 345 .

[10] H. T. Lemke et al, J. Phys. Chem. A. 2013, 117, 735.

[11] K. Haldrup et al, J. Phys. Chem. B 2016, 120,1158.

[12] E. Biasin et al, Phys. Rev. Lett. 2016, 117, 013002.

[13] A. L. Smeigh, M. Creelman, R. A. Mathies, J. K. McCusker, J. Am. Chem. Soc. 2008, 130, 14105.

[14] C. Consani, M. Prémont-Schwarz, A. EINahhas, Ch. Bressler, F. van Mourik, A. Cannizzo, M. Chergui, Angew. Chem. Int. Ed. 2009, 48, 7184; Angew. Chem. 2009, 121, 7320.

[15] G. Auböck, M. Chergui, Nat. Chem. 2015, 7, 629

[16] J. O. Johansson, J.-W. Kim, E. Allwright, D. M. Rogers, N. Robertson, J.-Y. Bigot, Chem. Sci. 2016, 7, 7061.

[17] M. Cammarata et al, Phys. Rev. Lett. 2014, 113, 227402.

[18] A. Marino, M. Cammarata, S. F. Matar, J.-F. Létard, G. Chastanet, M. Chollet, J. M. Glownia, H. T. Lemke, E. Collet, Struct. Dyn. $2016,3,023605$.

[19] A. Marino, M. Servol, R. Bertoni, M. Lorenc, C. Mauriac, J.-F. Létard, E. Collet, Polyhedron. 2013, 66, 123.

[20] R. L. Field, L. Liu, W. Gawelda, C. Lu, R. J. D. Miller, Chem. Eur. J. 2016, 22, 5118.

[21] E. Collet et al, Chem. Eur. J. 2012, 18, 2051

[22] R. Bertoni, M. Lorenc, H. Cailleau, A. Tissot, J. Laisney, M.-L. Boillot, L. Stoleriu, A. Stancu, C. Enachescu, E. Collet, Nat. Mater. $2016,15,606$.

[23] M. Gao et al, Nature 2013, 496, 343.

[24] M. Gao, Y. Jiang, G. H. Kassier, R. J. D. Miller, Appl. Phys. Lett. 2013, 103, 033503.

[25] P. Baum, D.-S. Yang, A. H. Zewail, Science 2007, 318, 788.

[26] B.-K. Yoo, Z. Su, J. M. Thomas, A. H. Zewail, Proc. Natl. Acad. Sci. U. S. A. 2016, 113, 503

[27] M. Hada, K. Pichugin, G. Sciaini, Eur. Phys. J.: Spec. Top. 2013, 222, 1093.

[28] H. M. Müller-Werkmeister, Y.-L. Li, E.-B. W. Lerch, D. Bigourd, J. Bredenbeck, Angew. Chem. Int. Ed. 2013, 52, 6214; Angew. Chem. 2013, $125,6334$.

[29] H. T. Lemke et al, Nat. Commun. 2017, 8, 15342.

[30] A. Hauser, N. Amstutz, S. Delahaye, A. Sadki, S. Schenker, R. Sieber, M. Zerara, Chimia. 2002, 56, 685

[31] V. Legrand, C. Carbonera, S. Pillet, M. Souhassou, J-F. Létard, P. Guionneau, C. Lecomte, J. Phys.: Conf. Ser. $2005,21,73$.

[32] N. Bréfuel, H. Watanabe, L. Toupet, J. Come, N. Matsumoto, E. Collet, K. Tanaka, J-P. Tuchagues, Angew. Chem. Int. Ed. 2009, 48, 9304; Angew. Chem. 2009, 121, 9468.

[33] N. Bréfuel, E. Collet, H. Watanabe, M. Kojima. N. Matsumoto, L. Toupet, K. Tanaka, J-P. Tuchagues, Chem. Eur. J. 2010, 16, 14060.

[34] P. Guionneau, Dalton Trans. 2014, 43, 382. 

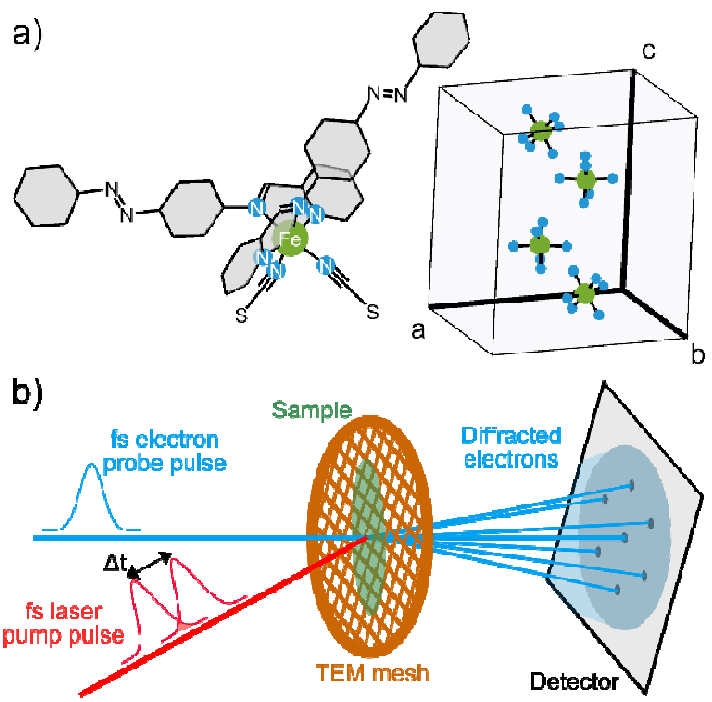

Figure 1. a) Low-spin molecular structure of $\left[\mathrm{Fe}(\mathrm{PM}-\mathrm{AzA})_{2}\right](\mathrm{NCS})_{2}$ arrangement of the $\mathrm{FeN}_{6}$ complexes within the crystallographic unit cell. b) Schematic of our femtosecond electron diffraction setup. ${ }^{[23]}$

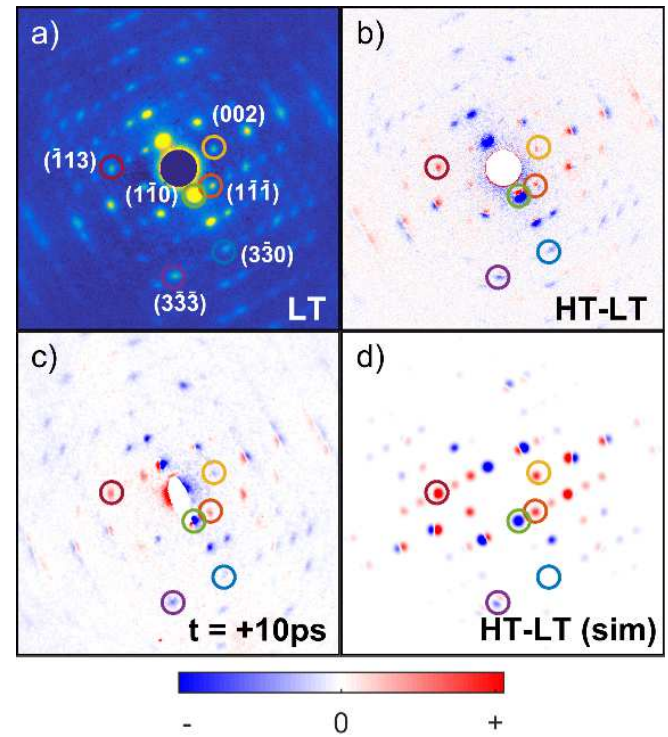

Figure 2. Comparative electron diffraction patterns with peaks of interest highlighted: a) data measured at low temperature $(T=170 \mathrm{~K})$; b) difference between LT and HT data; c) signal induced by photoexcitation, measured after 10 ps time delay; d) difference between LT and HT data, simulated using static X-ray diffraction structures. 

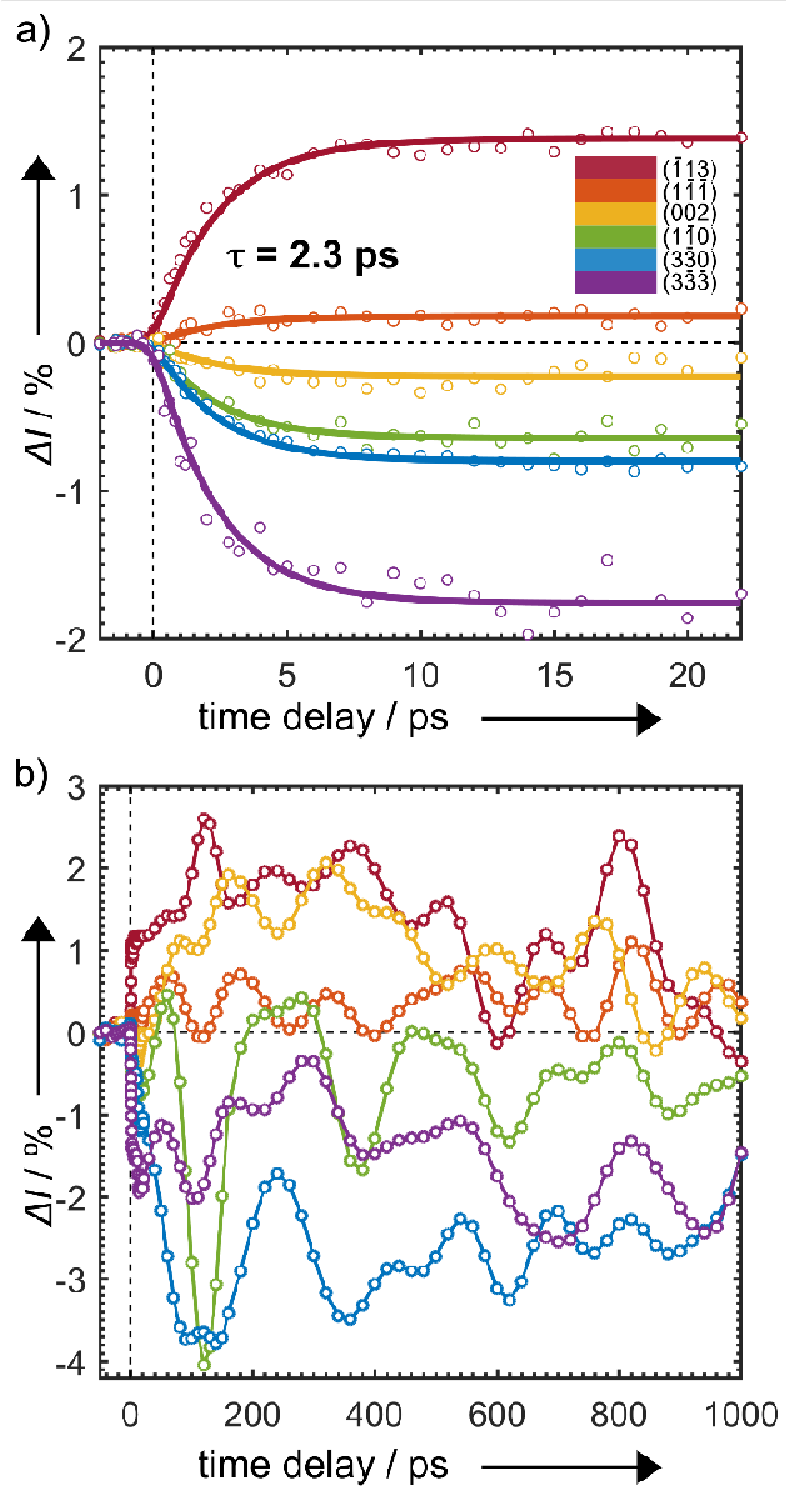

Figure 3. a) Short-time relative change in the intensity of select Bragg spots from $t=-5$ to $22 \mathrm{ps}$. b) Long-time relative change in the intensity from $t=-50$ to 1000 ps. Colors correspond to the highlighted peaks of interest in Figure 2. 

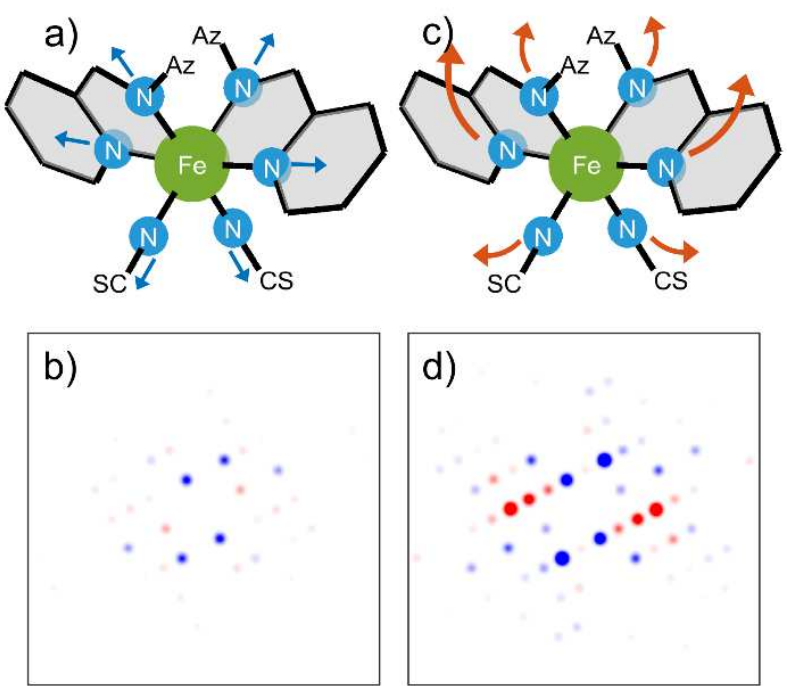

d)

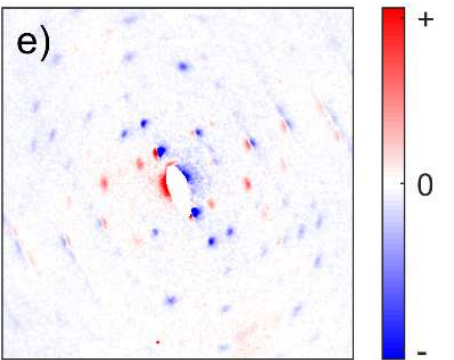

Figure 4. Model comparison. a) Model 1: Elongation of Fe-N coordination bond by an average of $0.2 \AA$ c) Model 2: Simultaneous nuclear motions from low-spin to high-spin structure. b), d), Simulated change in electron diffraction from model 1 and 2, respectively. e) Signal induced by photoexcitation.

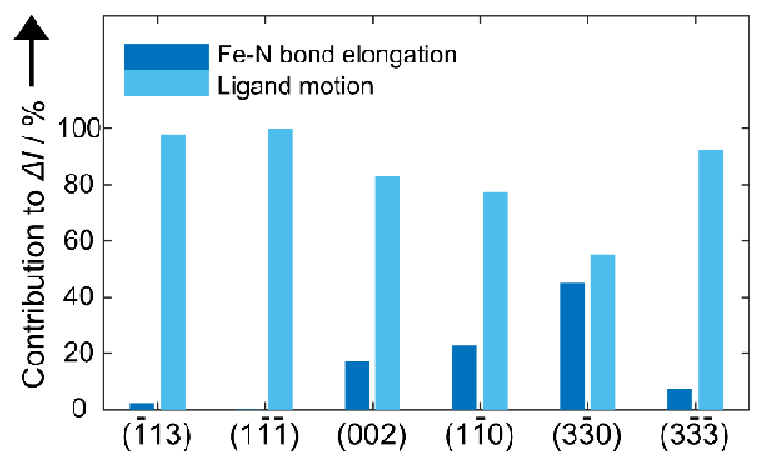

Figure 5. Contribution to relative intensity change. Comparing changes from $\mathrm{Fe}-\mathrm{N}$ bond elongation versus all other nuclear motions. 


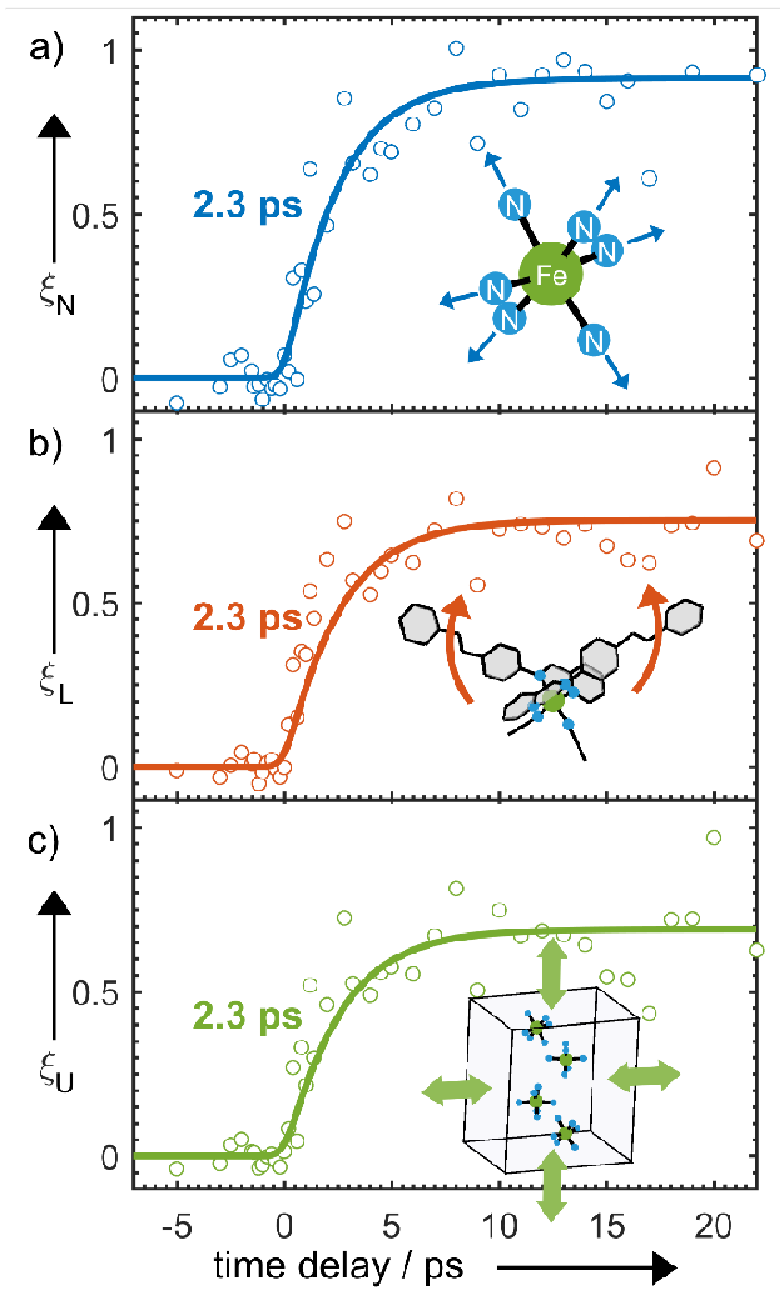

d)

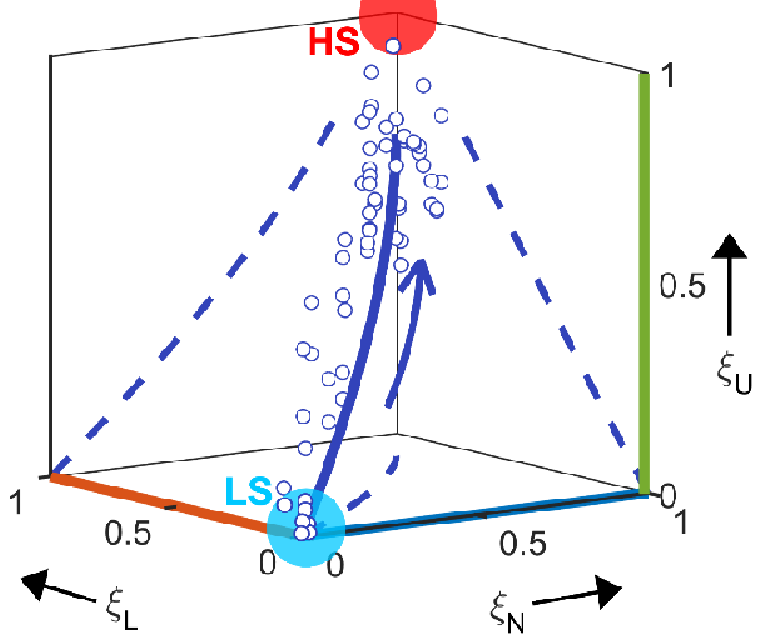

Figure 6. Molecular movie. a)-c), Time-dependence of refined reaction coordinates. d), Plot of independent refinement over reaction-coordinate space. 


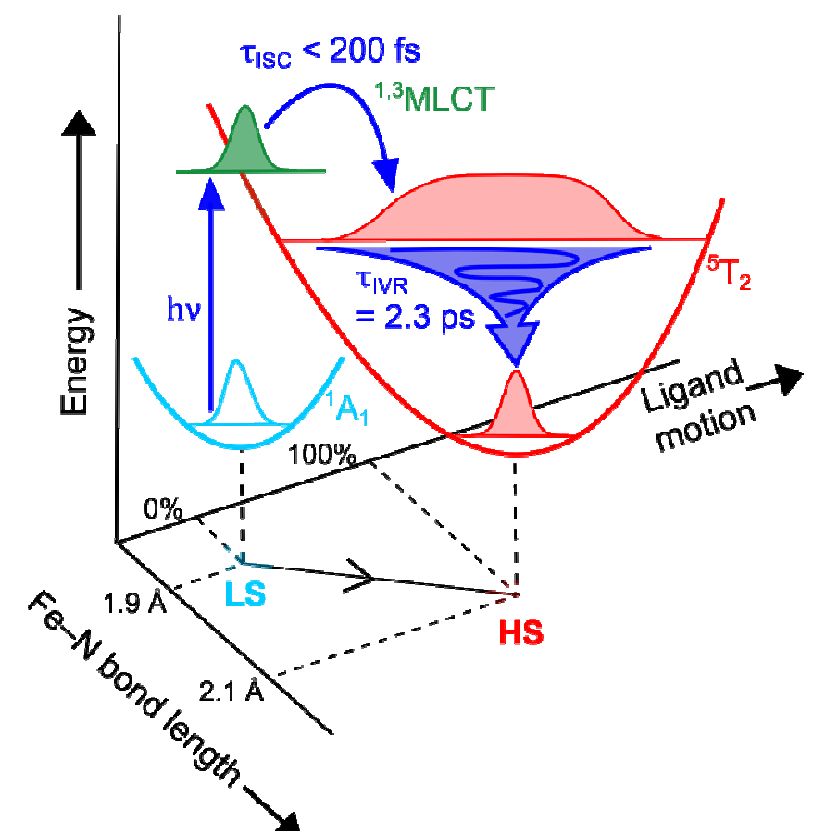

Figure 7. Schematic representation of the proposed reaction pathway of SCO in configuration space. Photoexcitation of the singlet ground state is followed by sub 200 fs ISC dynamics which put the molecule onto the quintet potential surface. This vibrationally hot $\mathrm{HS}$ state has a broad $\mathrm{Fe}-\mathrm{N}$ bond distribution, which narrows dramatically over 2.3 ps as IVR activates ligand motions and drives further reorganization of the cold unit cell. 